\title{
Transformation kinetics and microstructures of Ti17 titanium alloy during continuous cooling
}

\author{
Julien Da Costa Teixeira ${ }^{\mathrm{a}, \mathrm{c}}$, Benoît Appolaire ${ }^{\mathrm{a}, 1}$, \\ Elisabeth Aeby-Gautier ${ }^{a}$, Sabine Denis ${ }^{\mathrm{a}}$, \\ ${ }^{a}$ LSG2M, École des Mines de Nancy, Parc de Saurupt, 54042 Nancy Cedex, \\ France \\ Georges Cailletaud ${ }^{\mathrm{b}}$, \\ ${ }^{\mathrm{b}}$ Centre des Matériaux, Ecole des Mines de Paris, UMR CNRS 7633, BP97, \\ 91003 Evry Cedex, France \\ Nadine Späth ${ }^{\mathrm{c}}$ \\ ${ }^{\mathrm{c}}$ Snecma, 171 Bd de Valmy - BP 31, 92702 Colombes Cedex, France
}

\begin{abstract}
We have investigated the microstructure evolutions in the Ti17 near $\beta$ titanium alloy during heat treatments. The phase transformation has first been studied experimentally by combining X-Ray diffraction analysis, electrical resistivity and microscopy observations. From a series of isothermal treatments, a IT diagram has been determined, which takes into account the different morphologies. Then, a JohnsonMehl-Avrami-Kolmogorov (JMAK) model has been successfully used to describe
\end{abstract}


the phase transformation kinetics during either isothermal or cooling treatments. Finally, the coupling of the JMAK model to the Finite element software ZeBuLoN allowed us to investigate the evolution of the spatial distribution of the different morphologies during the cooling of an aircraft engine shaft disk after forging.

Key words: titanium alloy, phase transformation, kinetics, JMAK, coupled calculation

\section{Introduction}

Most titanium alloys have been designed for aeronautical applications, where their excellent specific properties are fully employed. For example TA6V, Ti17, Ti6242S or TA6Zr5D alloys are used for the manufacturing of aircraft engine components whose service temperature does not exceed $500{ }^{\circ} \mathrm{C}$, as shaft disks and blades, or casings. These alloys, which are designed mainly through low cycle fatigue resistance and creep [1], have mechanical properties widely influenced by their microstructure at each stage of the thermomechanical treatment [2]. The optimization of the mechanical properties for each specific use thus requires the knowledge of these evolutions.

This work aims at predicting the microstructure evolutions associated with the phase transformations inside Ti17 industrial slugs, during their thermomechanical treatments. Indeed, with the knowledge of the microstructure evolutions, the development step can be optimized, the reliability of the processes improved and the production costs thus reduced.

In this study, we focus on the cooling treatment following the hot deforma-

$\overline{1}$ Corresponding author. Tel: (33) (0)3 83584220 Fax: (33) (0)3 83584056. e-mail: benoit.appolaire@mines.inpl-nancy.fr 
tion, in the $\beta$ phase field. During the cooling, the equilibrium volume fraction of $\alpha$ phase increases from $0 \%$ at the transus temperature up to a maximum value of $67 \%$ at room temperature. As a near beta alloy, the Ti17 alloy can retain, if quenched quickly, the whole $\beta$ phase at a metastable state. For lower cooling rates, the volume fraction, the morphology and the distribution of the $\alpha$ precipitates depend on the cooling conditions.

The outline of the paper is as follows: at first, the microstructure evolution associated with the phase transformation is studied inside small samples undergoing isothermal treatments. Then the phase transformation kinetics is modelled with a global JMAK (Johnson-Mehl-Avrami-Kolmogorov) law whose parameters are deduced from the isothermal experiments, following a procedure undertaken for other kinds of alloys (e.g. steels, superalloys) [3]. Then, large parts are considered, where the necessary coupling between the thermal and metallurgical evolutions have been taken into account. Finally, the computed results are compared to experiments and discussed.

\section{Experiments}

\subsection{Material}

The chemical composition of the billet used in our experiments has been measured by Timet Savoie, and it has been checked that the chemical macrosegregation is negligible between the top and the bottom of the billet (Tab. 1). According to X-Ray diffraction measurements, the billet is composed of $33 \%$ of $\beta$ phase and $67 \%$ of $\alpha$ phase. Morphological grain sizes are 5 and 8 to $10 \mu \mathrm{m}$ diameter respectively for $\alpha$ and $\beta$ transformed $\left(\beta_{\mathrm{t}}\right)$ phases. Two morphologies 
of the $\alpha$ phase are observed (Fig. 1): large grains $\left(\alpha_{\mathrm{P}}\right)$ located at the grain boundaries of the $\beta_{\mathrm{t}}$ phase; and small laths and needles $\left(\alpha_{\mathrm{S}}\right)$ in the parent $\beta$ grains. This bimodal microstructure results from a thermomechanical treatment under the transus temperature. In the following, this microstructure will be referred to as "initial".

\subsection{Thermal treatments}

Two kinds of treatments were performed on small samples: isothermal treatments at temperatures between 400 and $825^{\circ} \mathrm{C}$; and continuous cooling treatments at cooling rates between 0.02 and $1^{\circ} \mathrm{C} / \mathrm{s}$ (Fig. 2). All treatments were preceded by a solution treatment in the $\beta$ field, leading to a microstructure composed of $\beta$ grains with diameters ranging from 150 to $200 \mu \mathrm{m}$. The quench-

ings from the solution treatment to the isothermal holdings were performed by helium blowing with durations shorter than $10 \mathrm{~s}$.

These thermal treatments were performed on a in house quenching dilatometer, heating under secondary vacuum with a pressure lower than $10^{-4}$ mbar. The samples were taken from the billet by spark machining with dimensions of $30 \mathrm{~mm}$ long and $3 \mathrm{~mm}$ diameter ensuring homogeneous temperatures during the treatments.

\subsection{In-situ kinetics measurements}

Because the dilatometry is poorly sensitive to the phase transformation $\beta \leftrightarrow \alpha$, the electrical resistivity was measured and analyzed following different methods for isothermal and cooling treatments in order to get the transformation 
kinetics [4-7].

In the case of isothermal treatments, the transformation was considered as complete when the electrical resistivity remains constant. Assuming that the electrical resistivity of each phase is constant and that the overall alloy resistivity follows a mixture rule, the transformed volume fraction is:

$$
\xi=\frac{f^{\alpha}}{f_{\text {end }}^{\alpha}}=\frac{\rho-\rho_{0}}{\rho_{\mathrm{end}}-\rho_{0}}
$$

where $\rho, \rho_{0}$ and $\rho_{\text {end }}$ are the resistivities respectively during, at the beginning, and at the end of the isothermal treatment. $f^{\alpha}$ and $f_{\text {end }}^{\alpha}$ are the current and the final $\alpha$ volume fractions, this last quantity being measured by X-Ray diffraction after quenching the specimen.

In the case of non-isothermal treatments, the procedure described in [5] has been applied.

To confirm the resistivity measurements, those have been compared to XRay diffraction measurements on samples quenched at different times of the treatment [8].

\subsection{Post-mortem characterisation}

At the end of the thermal treatments, microstructural observations were carried out by optical microscopy and scanning electron microscopy (SEM), using a Philips XL30 SFEG in both secondary electron (SE) and back scattered electron (BSE) imaging modes.

X-Ray diffraction analyses were also undertaken. The X-Ray diffraction patterns were obtained either with a cobalt anode $(\lambda=1.78897 \AA, 35 \mathrm{kV}$ and 20 
$\mathrm{mA})$, or with a copper anode $(\lambda=1.54184 \AA, 40 \mathrm{kV}$ and $25 \mathrm{~mA})$. The diffraction peaks of the $\alpha$ and $\beta$ phases were obtained in a $2 \theta$ range of respectively $\left[35^{\circ}, 110^{\circ}\right]$ and $\left[30^{\circ}, 145^{\circ}\right]$. In order to limit the error associated with the large parent grain size, $15 \theta-2 \theta$ scans were collected with $\chi$ varying from 0 to $45^{\circ}$ for each analysis. The volume fraction of each phase was taken as proportional to the area under the associated diffraction peaks. Some scans have also been analyzed using the Rietveld method [9]. The experimental errors have been estimated to be inferior to $2 \%$ of $\alpha$ volume fraction.

\subsection{Equilibrium data}

The first data necessary for the model are the transus temperature and the equilibrium $\alpha$ volume fraction $f_{\text {eq }}^{\alpha}$ versus temperature.

A transus temperature of $880^{\circ} \mathrm{C}$ has been determined by Timet from microstructure observations. For the determination of $f_{\mathrm{eq}}^{\alpha}$ versus temperature, two kinds of thermal treatments have been performed. In the first kind, samples at the initial state have been solutionized at $870{ }^{\circ} \mathrm{C}$, and then submitted to isothermal treatments (ranging from 700 to $830^{\circ} \mathrm{C}$ ) long enough to reach the equilibrium state (lasting up to 100 hours). $f^{\alpha}$ has been measured by quantitative image analysis on SEM micrographs with an uncertainty of $1 \%$ (Fig. 3 with open squares).

In the second kind, the samples have been solution treated in the $\beta$ field, and then transformed isothermally until the electrical resistivity remains constant. $f^{\alpha}$ has been measured by X-ray diffraction, as well as by image analysis for 3 temperatures: 800,750 and $700{ }^{\circ} \mathrm{C}$.

For both kinds of treatments, the measured $f^{\alpha}$ are very close. It can thus 
be safely assumed that the equilibrium state is reached at the end of all our isothermal treatments. The equilibrium $\alpha$ volume fraction versus temperature is well described by the following empirical rule $[5,10]$ :

$$
f_{\mathrm{eq}}^{\alpha}(T)=f_{\mathrm{eq}}^{\alpha}\left(20^{\circ} \mathrm{C}\right)\left\{1-\exp \left[-A\left(T-T_{\beta}\right)\right]\right\}
$$

with $f_{\mathrm{eq}}^{\alpha}\left(20^{\circ} \mathrm{C}\right)=0.67, A=0.01015, T_{\beta}=880^{\circ} \mathrm{C}$, and $\mathrm{T}$ the temperature in Celsius. The parameters $f_{\mathrm{eq}}^{\alpha}\left(20^{\circ} \mathrm{C}\right)$ and $A$ are determined from the best fit of the experimental values by the least squares method.

\subsection{Isothermal transformations}

\subsubsection{Kinetics}

In the case of a solution treatment for 30 min., the IT diagram has been determined from in-situ electrical resistivity measurements during successive isothermal treatments (Fig. 4).

Three temperature ranges can be observed where the start times $t_{\mathrm{S}}$ follow different $\mathrm{C}$ curves in Fig. 4. These ranges correspond to different morphologies of the $\alpha$ phase. The respective 'noses' of the $\mathrm{C}$ curves are located at about 750,650 and $450{ }^{\circ} \mathrm{C}$. It can be noticed that the diagram is similar to what has been obtained by Bein for the $\beta$-Cez alloy [11], except for a few differences in the temperatures of the 'noses' which can be attributed to the difference in the transus temperatures. 


\subsubsection{Morphologies}

Two morphologies, $\alpha_{\mathrm{GB}}$ (for $\alpha$ Grain Boundary) and $\alpha_{\mathrm{WGB}}$ (for $\alpha$ Widmanstätten Grain Boundary), are observed above $750^{\circ} \mathrm{C}$, hence related to the first $\mathrm{C}$ curve. The $\alpha_{\mathrm{GB}}$ morphology lies along the grain boundaries (Fig. 5), which are probably the only nucleation sites at these high temperatures because of the low available driving force. The $\alpha_{\mathrm{WGB}}$ morphology is composed of colonies of parallel $\alpha$ plates with often only one crystallographic orientation. The colonies have systematically grown from the $\alpha_{\mathrm{GB}}$.

The morphology $\alpha_{\mathrm{WI}}(\alpha$ Widmanstätten Intragranular) is observed between 550 and $700{ }^{\circ} \mathrm{C}$. It is associated with the second $\mathrm{C}$ curve. This morphology is acicular (Fig. 6). But contrary to $\alpha_{\mathrm{WGB}}$, the precipitates are not gathered in colonies but form wave-basket patterns. Fig. 7 shows clearly that the number of $\alpha_{\mathrm{WI}}$ precipitates increases progressively inside the $\beta$ grains, toward the center of the grains.

Under $525^{\circ} \mathrm{C}$ the third $\mathrm{C}$ curve corresponds to another intragranular morphology forming herring bone patterns (Fig. 8), which has been attributed to a "third transformation mechanism" involving a sympathetic nucleation process $[4,12]$.

\subsection{Continuous cooling treatments}

\subsubsection{Kinetics}

The evolution of the $\alpha$ volume fraction has been measured by electrical resistivity during different cooling treatments at the following cooling rates: 0.02 , 
$0.05,0.1,0.5,0.75$ and $1^{\circ} \mathrm{C} / \mathrm{s}$. To check the kinetics obtained by resistivity, the measurements at $1^{\circ} \mathrm{C} / \mathrm{s}$ were also obtained using X-Ray diffraction on as quenched samples. All the results are plotted in Figure 9.

Despite the fact that resistivity measurements are global, it is possible to determine the temperature ranges where each morphology appears. For instance for $0.05^{\circ} \mathrm{C} / \mathrm{s}$, the phase transformation begins at $800^{\circ} \mathrm{C}$, proceeds slowly down to $700{ }^{\circ} \mathrm{C}$, then accelerates down to $650{ }^{\circ} \mathrm{C}$ where the equilibrium is reached (Fig. 9). From the previous microstructural observations, the first stage between 800 and $700{ }^{\circ} \mathrm{C}$ is due to the precipitation of $\alpha_{\mathrm{GB}}$ and $\alpha_{\mathrm{WGB}}$. The acceleration at $700^{\circ} \mathrm{C}$ comes from the precipitation of $\alpha_{\mathrm{WI}}$. For each morphology, the temperature at which the precipitation starts decreases as the cooling rate increases. Similarly, the temperature at which the equilibrium fraction is reached decreases when the cooling rate increases. For cooling rates greater than $0.75^{\circ} \mathrm{C} / \mathrm{s}$, it must be noticed that the equilibrium fraction $f_{\text {eq }}^{\alpha}$ is never reached.

\subsubsection{Morphologies}

For all cooling rates, the microstructure has been observed at the end of the treatment, except for the cooling rate at $1^{\circ} \mathrm{C} / \mathrm{s}$, where interrupted treatments were also performed. $f^{\alpha}$ has been measured by X-Ray diffraction and the volume fraction of each morphology has been deduced from the microstructure observations. The results are reported in figure 10 .

First, one can notice the absence of the third morphology whatever the cooling rate. $\alpha_{\mathrm{GB}}$ and $\alpha_{\mathrm{WGB}}$ are preponderant at the lowest cooling rate $0.02{ }^{\circ} \mathrm{C} / \mathrm{s}$. Their volume fraction then decreases as the cooling rate increases. At 0.75 and 
$1^{\circ} \mathrm{C} / \mathrm{s}$, they are still observable but negligible. The $\alpha_{\mathrm{WI}}$ volume fraction has been calculated by substracting the volume fraction of $\alpha_{\mathrm{GB}+\mathrm{WGB}}$ to the global one. This morphology coexists with $\alpha_{\mathrm{GB}}$ and $\alpha_{\mathrm{WGB}}$ for 0.02 to $0.1^{\circ} \mathrm{C} / \mathrm{s}$. It then dominates at cooling rates higher or equal to $0.5^{\circ} \mathrm{C} / \mathrm{s}$. These observations are consistent with the results of the isothermal treatments. As well, similar evolutions had already been observed for the $\beta$-Cez alloy [13] and the Ti17 $[4]$.

In order to show the interactions between $\alpha_{\mathrm{GB}+\mathrm{WGB}}$ and $\alpha_{\mathrm{WI}}$ during a cooling treatment, figure 11 compares the final microstructures obtained with two different cooling rates: 0.75 and $1^{\circ} \mathrm{C} / \mathrm{s}$. At that rates, both kind of morphologies can be observed and can be considered appearing successively. It seems that the vicinity of the grain boundaries are preferential nucleation sites for the $\alpha_{\text {WI }}$ precipitates, although some can also be observed far inside the grains. Interactions between $\alpha_{\mathrm{WGB}}$ and $\alpha_{\mathrm{WI}}$ are thus likely to occur: $\alpha_{\mathrm{WI}}$ needles would stop the growth of $\alpha_{\text {WGB }}$ plates and, conversely the growth of the $\alpha_{\text {WGB }}$ plates would reduce the number of available nucleation sites for $\alpha_{\mathrm{WI}}$ in the vicinity of the grain boundaries. Nonetheless, it seems that these interactions are limited to hard impingement. This conclusion is corroborated by microprobe measurements of the diffusion lengths of the alloying elements in the front of the $\alpha_{\text {WGB }}$ colonies [14]: for $200 \mu \mathrm{m}$ grains, the diffusion lengths of $\mathrm{Al}$ were less than $20 \mu \mathrm{m}$ and $3 \mu \mathrm{m}$ at respectively 830 and $750^{\circ} \mathrm{C}$. 


\section{Modeling of the phase transformations}

\subsection{Description of the model}

The model relies on the following assumptions:

(i) the interactions between the $\alpha$ precipitates are limited to hard impingement, as suggested by the measurements mentionned above of the diffusion lengths of alloying elements in front of the growing $\alpha_{\mathrm{WGB}}$ lamellae colonies.

(ii) The morphologies $\alpha_{\mathrm{GB}}$ and $\alpha_{\mathrm{WGB}}$ are treated as a whole in the model, and noted $\alpha_{\mathrm{GB}+\mathrm{WGB}}$. Indeed, the $\alpha_{\mathrm{GB}}$ morphology is absolutely necessary for the appearance of $\alpha_{\mathrm{WGB}}$.

(iii) The isothermal transformation kinetics can be predicted with the JMAK law, which was relevant for several other titanium alloys [12,15-17]. For the Ti17 alloy, its validity has been checked from the electrical resistivity measurements.

The calculations are carried out step by step, following the work of $[18,19]$. First, the extended volume $V_{i}^{\mathrm{e}}$ containing a mixture of $\alpha$ and $\beta$ phases locally at equilibrium is calculated for each possible morphology as in [20]:

$$
V_{i}^{\mathrm{e}}=V k_{i}\left(t-t_{\mathrm{S}_{i}}\right)^{n_{i}}
$$

with $n_{i}$ and $k_{i}$ the JMAK coefficients, $t_{\mathrm{S}_{i}}$ the beginning time for the appearance of morphology $i$, and $V$ the total volume.

Second, the true transformed volume $V_{i}$ of morphology $i$ is deduced from the extended one:

$$
d V_{i}=\left(1-\frac{\sum_{j} V_{j}}{V}\right) d V_{i}^{\mathrm{e}}
$$


Third, the $\alpha$ phase volume fraction can be calculated assuming that the transformed volume is at local equilibrium, as suggested by the experiments. Hence, the volume fraction $f_{i}^{\alpha}$ corresponding to morphology $i$ is:

$$
f_{i}^{\alpha}=\frac{V_{i}}{V} f_{\text {eq }}^{\alpha}(T)
$$

where $f_{\mathrm{eq}}^{\alpha}$ is the equilibrium $\alpha$ phase volume fraction which does not depend on the morphology.

Anisothermal treatments are decomposed into a succession of short isothermal steps where the transformation progression is computed with the JMAK law $[15,16]$. To do this, it is necessary to assume that the transformation beginning and progression are additive, i.e. [21]:

(i) the beginning time of the transformation is calculated with Scheil method:

$$
S_{i}=\int \frac{d t}{t_{\mathrm{S}_{i}}(T)}
$$

where $S_{i}$ is the so-called sum of Scheil of morphology $i$. When $S_{i}$ reaches the value of 1 , morphology $i$ begins to precipitate.

(ii) The transformation rate never depends on the former thermal path, but only on the current $\alpha$ phase amount and temperature. This assumption has been verified experimentally for the growth of $\left(\alpha_{\mathrm{GB}+\mathrm{WGB}}\right)$ [7]. In that case, the transformed volume rate of morphology $i$ reads:

$$
d_{t} V_{i}=f\left(T, f^{\alpha}\right)
$$

where $f^{\alpha}=\sum_{i} f_{i}^{\alpha}$, and $d_{t}$ denotes time derivation.

It must be noticed that the volume of $\alpha$ inside a transformed volume is assumed to be in local equilibrium with $\beta$, and is thus calculated with Eq. (5). 
But because the equilibrium $\alpha$ volume fraction increases during cooling (Fig. 3), there may be a delay to reach the equilibrium volume fraction all the more the growth process is slow. However, calculations based on nucleation-growth laws have shown that the growth rate is high enough, at least above $700{ }^{\circ} \mathrm{C}$, for neglecting the delay [22].

Ten different experimental input data versus temperature are necessary: the equilibrium $\alpha$ phase volume fraction $f_{\text {eq }}^{\alpha}$; and the JMAK coefficients $t_{s_{i}}, n_{i}$ and $k_{i}$ for each morphology. The kinetics data have been determined from electrical resistivity measurements during isothermal treatments [8]. The values are in the range of those commonly obtained. But they do not follow a clear variation with temperature as it may be expected from [20]. The same observation has been made for other titanium alloys [23,24] considering the global $\alpha$ phase amount. As we model the transformation kinetics for each morphology, similarly to [15], constant values of $n$ are assumed for each morphology (see Tab. $2)$.

Finally, the model has been implemented into the finite element code ZeBuLoN through the ZebFront interface [25].

\subsection{Comparison with experiments}

For isothermal treatments, the calculated $\alpha$ phase volume fractions versus time are compared to the experiments in Fig. 12.

At $800^{\circ} \mathrm{C}$, a good agreement is achieved for the whole transformation duration. In agreement with the observations, the only "morphology" to appear is $\alpha_{\mathrm{GB}+\mathrm{WGB}}$. Nonetheless, at the beginning, there are discrepancies up to $15 \%$ 
(with X-Ray diffraction) and 10\% (with electrical resistivity). These discrepancies can be attributed to the measurement uncertainties, as well as to the fitting procedure of the JMAK coefficients [8].

At $725^{\circ} \mathrm{C}, \alpha_{\mathrm{GB}+\mathrm{WGB}}$ is the first morphology to appear. Then, after $300 \mathrm{~s}, \alpha_{\mathrm{WI}}$ precipitates, in agreement with the experimental observations. At this temperature, the predicted final volume fraction of $\alpha_{\mathrm{GB}+\mathrm{WGB}}$ is also in agreement with the experimental observations.

At $600{ }^{\circ} \mathrm{C}$, the duration of the transformation is in agreement with the experimental results. As observed in the micrographs, $\alpha_{\mathrm{WI}}$ is the only morphology present. Nonetheless, there is a large discrepancy between calculations and experiments concerning the beginning time. This can be attributed again to the fitting procedure of the JMAK coefficients, as well as to the experimental measurement uncertainties, as illustrated in Fig. 12c by the two resistivity curves for the same treatment.

Calculations of the $\alpha$ morphologies volume fraction have then been performed for coolings at constant rates and compared to experimental results. In Fig. 13, typical results are illustrated.

For a cooling rate of $0.02{ }^{\circ} \mathrm{C} / \mathrm{s}$, a very good agreement is achieved, the discrepancies remaining lower than $f_{\alpha}=12 \%$. As observed, the final microstructure is composed of $\alpha_{\mathrm{GB}+\mathrm{WGB}}$ and of little $\alpha_{\mathrm{WI}}$. The use of the additivity rule when $\alpha_{\mathrm{GB}+\mathrm{WGB}}$ is almost the only morphology to precipitate is then justified.

For a cooling rate of $0.05^{\circ} \mathrm{C} / \mathrm{s}$, a fair agreement is achieved, the differences in $f_{\alpha}$ being at most $10 \%$. The final microstructure is predicted to be composed of $\alpha_{\mathrm{GB}+\mathrm{WGB}}$ and of $\alpha_{\mathrm{WI}}$ with proportions very close to the measured ones. Nonetheless, the volume fraction of $\alpha_{\mathrm{GB}+\mathrm{WGB}}$ is overestimated between 700 and $800^{\circ} \mathrm{C}$. This is mostly due to an inherent failure of the JMAK formulation 
to account for heterogeneities in the spatial distribution of the precipitates. Indeed, the notion of extended volume is unable to discriminate between the precipitates growing near the grain boundaries and those inside the $\beta$ grains. And it is observed (e.g. Fig. 7) that $\alpha_{\mathrm{WI}}$ appears preferentially in the vicinity of the grain boundaries, and is likely to stop the growth of $\alpha_{\mathrm{WGB}}$.

For a cooling rate of $0.75^{\circ} \mathrm{C} / \mathrm{s}$, the temperature range of the phase transformation is well predicted. Moreover, the calculated proportion of each morphology is in qualitative agreement with the micrograph in Fig. 11a: the volume fraction of $\alpha_{\mathrm{GB}+\mathrm{WGB}}$ is indeed very small. But again, the model overestimates the transformation rate, as well as the final $f^{\alpha}$, for the same reasons as before.

Figure 14 summarizes all the calculations performed: the final volume fraction $f^{\alpha}$ as well as the final volume fraction of the different morphologies have been plotted versus cooling rates. They agree well with the experimental data of [14], except for a systematical overestimation of the final $f^{\alpha}$. This discrepancy can be attributed to the assumption made for calculating the volume fraction of $\alpha$ inside a transformed volume (Eq. 5): local equilibrium is assumed to hold at any temperature during a cooling, a condition unlikely to be maintained under about $700^{\circ} \mathrm{C}$, when the diffusion coefficients of the alloying elements become low [26]. By the way, as shown in Fig. 9, equilibrium is reached during cooling at temperatures lower than $700^{\circ} \mathrm{C}$.

Finally, it can be noted than the third morphology is predicted to be in very few proportion whatever the cooling rate, in agreement with the common experimental observations. 


\section{Coupled metallurgical and thermal calculations}

\subsection{Validation of the coupling}

First, experiments have been performed in order to test and validate the coupling between the temperature and metallurgical evolutions. Treatments generating gradients of microstructure have been applied to specimens with suitable sizes: cylinders $120 \mathrm{~mm}$ height and $40 \mathrm{~mm}$ diameter. The treatments start with a solution treatment for $30 \mathrm{~min}$. in air, followed by cooling using either water, oil, or air. 4 thermocouples were respectively inserted in the mid plane at 3, 7, 13 and $20 \mathrm{~mm}$ from the surface, and microstructures were observed by optical microscopy at the end of the treatments.

Moreover, the thermo-physical properties necessary for the calculations have been measured: the phase transformation enthalpy; and for both phases the densities, the specific heats and the thermal conductivities [8].

In the FEM calculations, an axisymetric $2 \mathrm{D}$ rectangular domain has been meshed with 8 nodes quadratic elements, with a spacing following a geometric progression along the radial direction, in order to accurately resolve the highest temperature gradients at the surface. Fourier conditions have been set at the boundaries. The same evolution of the heat transfer coefficient with temperature has been imposed at all the cylinder boundaries, which has been determined by fitting the calculated cooling curves to the measurements at 3 $\mathrm{mm}$ from the surface.

Quenchings in water and oil have first been studied. Calculations and measurements are compared in Figs. $15 \mathrm{a}$ and $15 \mathrm{~b}$ at the positions in the cylinder 
corresponding to the four thermocouples.

The highest cooling rates and the steepest temperature gradients are for the water quenching. For both quenchings, the cooling curves do not show any heat release associated with phase transformations. As expected, optical microscopy and X-Ray diffraction pattern do not reveal any $\alpha$ phase.

The calculations are in good agreement with the experiments for both quenchings. Indeed, the model does not predict any precipitation of the $\alpha$ phase. Nonetheless, cooling rates are slightly underestimated after about $20 \mathrm{~s}$ of cooling. The discrepancies could be attributed to either (i) the extrapolated thermophysical data of $\beta$ under the transus temperature [8]; (ii) the boundary conditions which are more complex than the assumed radial symmetry.

In figure 16, the predicted cooling curve is compared to the experimental one in the case of air cooling, only at the center of the cylinder. Indeed, all the cooling curves are very close to each others because the thermal gradients inside the samples are small. A satisfactory agreement is found. Fig. 16 also shows that $\alpha_{\mathrm{WI}}$ is about the only morphology to appear, as confirmed by micrographs of the final microstructure (Fig. 17). The calculations largely overestimate the $\alpha$ volume fraction measured by X-Ray diffraction which is only $11 \%$. Nonetheless, such an overestimation, already observed for the isothermal treatments, does not lead to a significant discrepancy in the cooling curves.

In order to test the model when $\alpha_{\mathrm{GB}+\mathrm{WGB}}$ precipitates, an air cooling treatment has been performed after an isothermal stage at $800^{\circ} \mathrm{C}$ for $6900 \mathrm{~s}$. The computed cooling curve is compared to the experimental one at the cylinder core in Fig. 18. An overall good agreement is achieved, despite a slight discrepancy under $570{ }^{\circ} \mathrm{C}$ due to the uncertainty in the heat transfer coefficient. 
The calculated $\alpha$ volume fraction is also plotted in the same figure. The $\alpha_{\mathrm{GB}+\mathrm{WGB}}$ volume fraction increases from $12 \%$ (obtained during the $800^{\circ} \mathrm{C}$ holding) to $30 \%$ during the first $150 \mathrm{~s}$. Then, it remains almost constant. After $150 \mathrm{~s}$, the precipitation of $\alpha_{\mathrm{WI}}$ starts and slows down the cooling due to the heat release, in agreement with the experimental cooling curve. Figure 19 shows the final microstructure. The almost equal proportions of $\alpha_{\mathrm{WI}}$ and $\alpha_{\mathrm{GB}+\mathrm{WGB}}$ observed in the micrographs (eg. Fig. 19) as well as measured by X-Ray diffraction (46\% of $\alpha_{\mathrm{GB}+\mathrm{WGB}}$ ) confirm the results of the calculations.

\subsection{Influence of heat release on the microstructure}

In order to illustrate the importance of heat release on the proportions of the different morphologies, we have again performed the calculation of an air cooling from $800^{\circ} \mathrm{C}$, but without heat release. The result is compared to the previous calculation with heat release in Fig. 20a. As expected, the cooling rates are higher during the precipitation of $\alpha_{\mathrm{WI}}$ when heat release is not accounted for (Fig. 20a). Consequently, the difference between the calculated and measured cooling curves greatly increases when $\alpha_{\mathrm{WI}}$ appears. In the same time, the precipitation of $\alpha_{\mathrm{WI}}$ is about half the one concomitant to heat release. Indeed, the cooling rate $\left(\right.$ about $1^{\circ} \mathrm{C} / \mathrm{s}$ ) is in the range where the microstructure evolution is the most sensitive to this parameter (Fig. 20b).

\subsection{Air cooling of a large industrial part}

Finally, the model has been applied to the air cooling of a shaft disk which has been heat treated in the $\beta$ temperature range and extruded. A cross section 
of the disk has been discretized with 715 triangular 3 nodes elements in the software FORGE2 ${ }^{\circledR}$, which has been used to compute the initial temperature field resulting from the extrusion process. As shown in Fig. 21, the meshes have been refined near the surface of the disk. The mesh file has then been imported from FORGE2 ${ }^{\circledR}$ to ZeBuLoN. Fourier conditions have been imposed at all the boundaries, with varying heat transfer coefficients along the surface, to account for the influence of the local curvature on the cooling.

At the end of the cooling, $f^{\alpha}$ is homogeneous and equal to $67 \%$ in the whole disk. On the contrary, the morphology is not homogeneous due to the differences in the cooling rate at the different locations in the disk: $\alpha_{\mathrm{GB}+\mathrm{WGB}}$ is predicted to be predominant in the core of the disk, whereas $\alpha_{\mathrm{WI}}$ is predominant near the surface (Fig. 21a).

So as to confirm these results, the microstructure has been observed by optical microscopy at two locations (Fig. 22). At point A near the surface,only very few $\alpha_{\mathrm{GB}+\mathrm{WGB}}$ and a majority of $\alpha_{\mathrm{WI}}$ is observed, in agreement with the predicted $f^{\alpha}$ values of $9 \%$ and $58 \%$ for $\alpha_{\mathrm{GB}+\mathrm{WGB}}$ and $\alpha_{\mathrm{WI}}$ respectively. This proportion can easily be explained by the cooling rate which is high near the surface. It can be noticed that $\alpha_{\mathrm{GB}}$ is predominantly observed at parent grain boundaries distorded during forging.

At point $\mathrm{B}$ in the core of the disk, $\alpha_{\mathrm{GB}+\mathrm{WGB}}$ is observed in greater proportion than at point $\mathrm{A}$, in agreement with the calculation which predicts $19 \%$ and $48 \%$ of $\alpha$ with respectively $\alpha_{\mathrm{GB}+\mathrm{WGB}}$ and $\alpha_{\mathrm{WI}}$ morphologies.

At point $\mathrm{C}$, close to point $\mathrm{B}$ and with a similar thermal path, the model predicts the same volume fractions of each morphology. However, the comparison with microstructural observations reveals a larger volume fraction of $\alpha_{\mathrm{GB}+\mathrm{WGB}}$, associated with the larger deformation (2.6 for point $\mathrm{C}$ against 1.2 
for point B) and with the formation of very small $\beta$ grains by recristallisation.

\section{Conclusion}

A complete investigation of the Ti17 alloy has been undertaken aiming at predicting the microstructure evolutions during the cooling processes of large industrial forged parts.

First, equilibium data as well as a IT diagram have been determined from careful experiments involving different techniques, i.e. microscopies together with image analysis, X-Ray diffraction analysis, and in-situ electrical resistivity. The kinetics data have been related to the different morphologies observed of the $\alpha$ phase. Then, the same techniques have been used to study the phase transformation during various cooling treatments, with an emphasis on the interaction between the different morphologies, especially the grain boundary Widmanstätten structures $\left(\alpha_{\mathrm{WGB}}\right)$ and intragranular acicular plates $\left(\alpha_{\mathrm{WI}}\right)$. Second, we have used these experimental results to feed a multi-morphology version of the JMA model. A good agreement has been achieved when comparing the model to the experimental kinetics, during either isothermal and continuous cooling treatments.

Finally, the JMA model has been coupled to the finite element code ZeBuLoN in order to simulate the coupling between temperature and phase transformation in large industrial parts where gradients are likely to be encountered. A complete validation of the coupling has been undertaken by comparison with experiments on large cylindrical specimens. Moreover, the coupling has been demonstrated to be non negligible. Then, we have been able to predict the microstructure evolution in an aircraft shaft disk, during its air cooling fol- 
lowing its forging. Due to large differences in the cooling rate from location to location, the predicted morphologies are heterogeneous in the disk. This is in a first order in agreement with the optical microscopy observations of a real disk.

Nevertheless the model does not take into account the effect of the prior plastic deformation on the microstructure, an effect which has been shown to be important for the morphologies [14]. Hence, work is currently under progress [27] to releave this limitation by improving a nucleation/growth model presented elsewhere [26].

\section{References}

[1] A. Barussaud, Y. Desvallees and J.Y. Guedou, In: P.A. Blenkinsop, W.J. Evans, H.M. Flowers (Eds.), Proceedings of the $8^{\text {th }}$ World Conference on Titanium, Birmingham, UK, The Institute of Materials, 1996, p. 1599.

[2] O. Gourbesville, Ph.D. Thesis, ENSAM, Paris, 2000.

[3] S. Denis, D. Farias and A. Simon, ISIJ Int. 32 (1992), p. 316.

[4] J. Béchet, B. Hocheid, In: G. Lütjering, U. Zwicker, W. Bunk (Eds.), Proceedings of the $5^{\text {th }}$ World Conference on Titanium, Deutsche Gesellschaft für Metallkunde, 1985, p. 1613.

[5] C. Angelier, S. Bein and J. Béchet, Metall. Trans. 28A (1997), p. 2467.

[6] C. Sauer and G. Lütjering, J. Mat. Proc. Technol. 111 (2001), p. 311.

[7] J. Da Costa Teixeira, L. Héricher, B. Appolaire, E. Aeby-Gautier, G. Cailletaud, S. Denis, N. Späth, J. Phys. IV France 120 (2004) p. 93.

[8] J. Da Costa Teixeira, Ph.D. Thesis, INPL, Nancy, 2005. 
[9] H. M. Rietveld, J. Appl. Cryst. 2 (1969), p. 65.

[10] R. Castro and L. Seraphin, Mem. Sci. Rev. Met. 12 (1966), p. 1025.

[11] S. Bein and J. Béchet, In: P.A. Blenkinsop, W.J. Evans, H.M. Flowers (Eds.), Proceedings of the $8^{\text {th }}$ World Conference on Titanium, Birmingham, UK, The Institute of Materials, 1996, p. 2353.

[12] S. Bein, Ph.D. Thesis, CNAM, Paris, 1996.

[13] S. Bein and J. Béchet, Revue de Métallurgie 93 (1996), p. 1079.

[14] E. Laude, Ph.D. Thesis, INPL, Nancy, 1997.

[15] E. Laude, E. Gautier, P. Archambault, S. Denis, Revue de Métallurgie 93 (1996), p. 1067; E. Laude, E. Gautier, S. Denis, In: P.A. Blenkinsop, W.J. Evans, H.M. Flowers (Eds.), Proceedings of the $8^{\text {th }}$ World Conference on Titanium, Birmingham, UK, The Institute of Materials, 1996, p. 2330.

[16] S. Malinov, Z. Guo, W. Sha and A. Wilson, Metall. Trans. 32A (2001), p. 879.

[17] S. Malinov, W. Sha et P. Markovsky, J. of Alloys and Compounds 348 (2003), p. 110.

[18] S. J. Jones and H. K. D. H. Bhadeshia, Acta Mat. 45 (1997), p. 2911.

[19] T. Reti, Z. Fried and I. Felde, Comput. Mat. Sc. 22 (2001), p. 261.

[20] J. W. Christian, The theory of transformations in metals and alloys, Part I, Second Ed., Pergamon Press, 1975.

[21] J. W. Cahn, Acta Met. 4 (1956), p. 572.

[22] L. Héricher, Ph.D. Thesis, INPL, Nancy, 2004.

[23] S. Malinov, P. Markovsky, W. Sha, Z. Guo, J. of Alloys and Compounds 314 (2001), p. 181. 
[24] S. Malinov, P. Markovsky et W. Sha, J. of Alloys and Compounds 333 (2002), p. 122 .

[25] J. Besson, R. Le Riche, R. Foerch, and G. Cailletaud, Revue Européenne des Éléments Finis 7 (1998), p. 567.

[26] B. Appolaire, L. Héricher, E. Aeby-Gautier, Acta Mat. 53 (2005), p. 3001.

[27] J. Da Costa Teixeira, B. Appolaire, E. Abey-Gautier, S. Denis, in preparation. 


\section{Tables}

Table 1. Chemical composition (wt. $\%$ except fo $\mathrm{O}_{2}$ in $\mathrm{ppm}$ ) of the Ti17 alloy in the billet.

\begin{tabular}{lcccccc}
\hline Alloying elements (wt \%) & $\mathrm{Al}$ & $\mathrm{Mo}$ & $\mathrm{Cr}$ & $\mathrm{Sn}$ & $\mathrm{Zr}$ & $\mathrm{O}_{2}(\mathrm{ppm})$ \\
\hline Nominal & 5 & 4 & 4 & 2 & 2 & \\
\hline bottom & 5.01 & 3.90 & 4.13 & 2.05 & 2.01 & 1205 \\
\hline top & 5.03 & 4.03 & 3.99 & 1.99 & 1.97 & 1225 \\
\hline
\end{tabular}

Table 2. Value of the JMAK n coefficient for each morphology of $\alpha$ phase.

$\alpha$ phase morphology JMAK coefficient $n$

\begin{tabular}{cc}
\hline$\alpha_{\mathrm{GB}+\mathrm{WGB}}$ & 1.3 \\
$\alpha_{\mathrm{WI}}$ & 1.6 \\
"Third morphology" & 1.5 \\
\hline
\end{tabular}




\section{Figure Captions}

Fig. 1. Initial microstructure ( $\alpha$ in dark).

Fig. 2. Thermal cycles for (a) isothermal treatments ; (b) cooling treatments.

Fig. 3. Equilibrium $\alpha$ volume fraction vs. temperature.

Fig. 4. IT diagram of the Ti17 alloy after a solution treatment for $30 \mathrm{~min}$, determined by electrical resistivity measurements.

Fig. 5. SEM observations of the microstructures obtained by an isothermal treatment at $750^{\circ} \mathrm{C}$ during (a) $360 \mathrm{~s}$ and (b) $9400 \mathrm{~s}$.

Fig. 6. SEM observations of the microstructure obtained by an isothermal treatment at $700{ }^{\circ} \mathrm{C}$ during $1500 \mathrm{~s}$.

Fig. 7. Optical observations of the microstructures obtained by an isothermal treatment at $700{ }^{\circ} \mathrm{C}$ for (a) $500 \mathrm{~s}$ and (b) $800 \mathrm{~s}$.

Fig. 8. SEM observations of the microstructure obtained by an isothermal treatment at $400^{\circ} \mathrm{C}$ during $4400 \mathrm{~s}$.

Fig. 9. Volume fraction of $\alpha$ vs. temperature for different cooling rates, obtained from X-Ray diffraction $\left(1^{\circ} \mathrm{C} / \mathrm{s}\right)$ and resistivity measurements (other rates). 
Fig. 10. Volume fraction of $\alpha$ and of $\alpha_{\mathrm{GB}+\mathrm{WGB}}$ at the end of the cooling treatment vs. cooling rate.

Fig. 11. Microstructures at the end of different cooling treatments: (a) $0.75^{\circ} \mathrm{C} / \mathrm{s}\left(\right.$ Optical); (b) $1^{\circ} \mathrm{C} / \mathrm{s},(\mathrm{SEM})$.

Fig. 12. Isothermal transformation kinetics at (a) 800, (b) 725 and (c) $600{ }^{\circ} \mathrm{C}$. Comparison between resistivity (open symbols), X-Ray Diffraction analysis (triangles) and calculations (continuous lines).

Fig. 13. Transformation kinetics during continuous cooling treatments at rates of (a) $0.02^{\circ} \mathrm{C} / \mathrm{s}$, (b) $0.05^{\circ} \mathrm{C} / \mathrm{s}$ and (c) $0.75^{\circ} \mathrm{C} / \mathrm{s}$. Comparison between resistivity (open squares) and calculations (continuous lines).

Fig. 14. Final volume fractions $f^{\alpha}$ of the different morphologies vs. cooling rates.

Fig. 15. Cooling curves at different locations during (a) water quenching; (b) oil quenching. The position are respectively $20,13,7$ and $3 \mathrm{~mm}$ along the radius from the surface. Dots are for the experiments and continuous lines for the calculations. The curve calculated at the surface is also given.

Fig. 16. Cooling curves (dots for experiments and continuous line for calculations) and calculated $\alpha_{\mathrm{WI}}$ volume fraction evolution during an air cooling.

Fig. 17. Optical micrograph of the microstructure at the end of an air cooling. 
Fig. 18. Cooling curves (dots for the experiment and continuous line for the calculation) and calculated time evolution of the $\alpha$ phase volume fraction during an air cooling from $800^{\circ} \mathrm{C}$.

Fig. 19. Optical micrograph of the final microstructure at the end of an air cooling from $800^{\circ} \mathrm{C}$.

Fig. 20. (a) Cooling curves during an air cooling from $800^{\circ} \mathrm{C}$ : experiment, calculations with, and without heat release; (b) predicted $\alpha$ volume fractions.

Fig. 21. Mesh superimposed to the final map of $\alpha_{\mathrm{WI}}$ volume fraction in a shaft disk.

Fig. 22. Final microstructures observed by optical microscopy at points (a) A and (b) B in Fig. 21. 


\section{Figures}

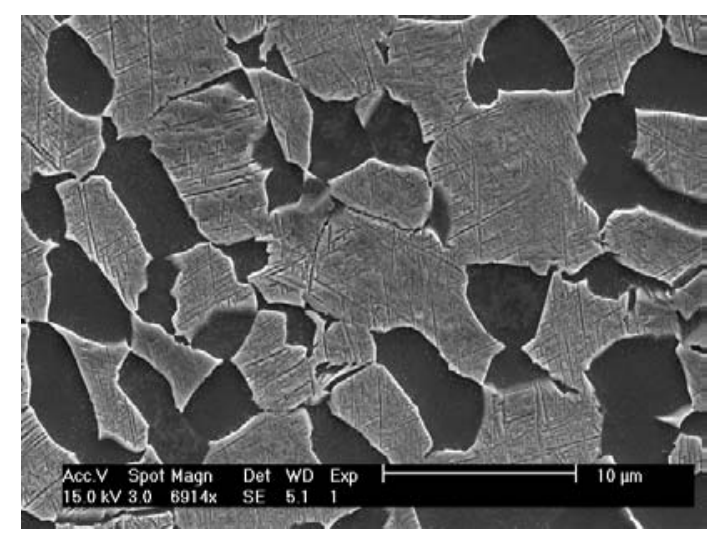

Fig. 1. Initial microstructure ( $\alpha$ in dark).

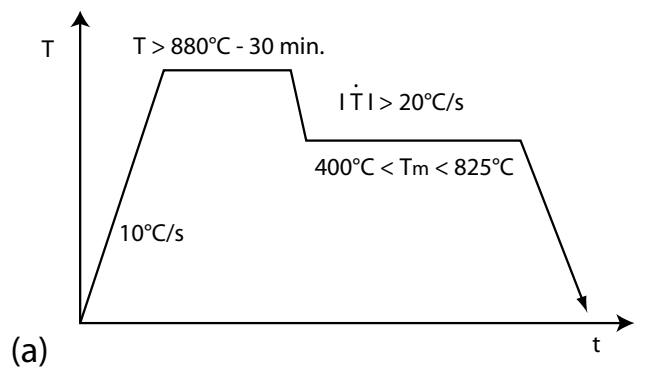

(b)

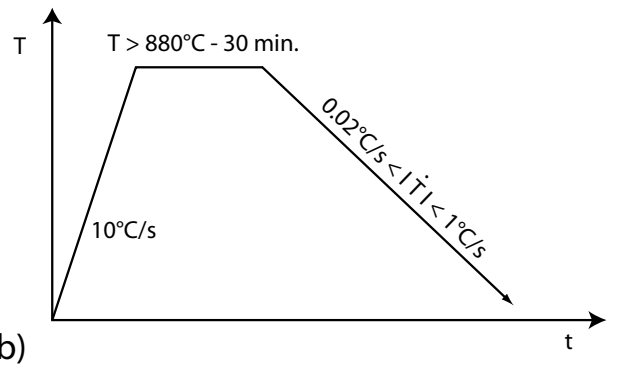

Fig. 2. Thermal cycles for (a) isothermal treatments ; (b) cooling treatments.

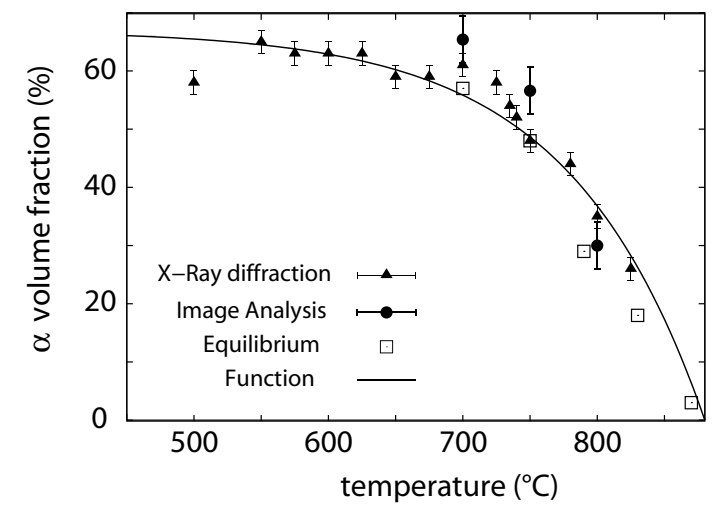

Fig. 3. Equilibrium $\alpha$ volume fraction vs. temperature. 


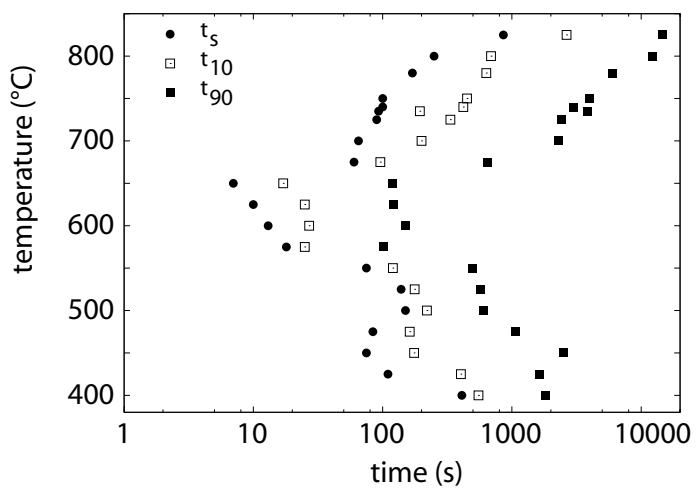

Fig. 4. IT diagram of the Ti17 alloy after a solution treatment for 30 min., determined by electrical resistivity measurements.
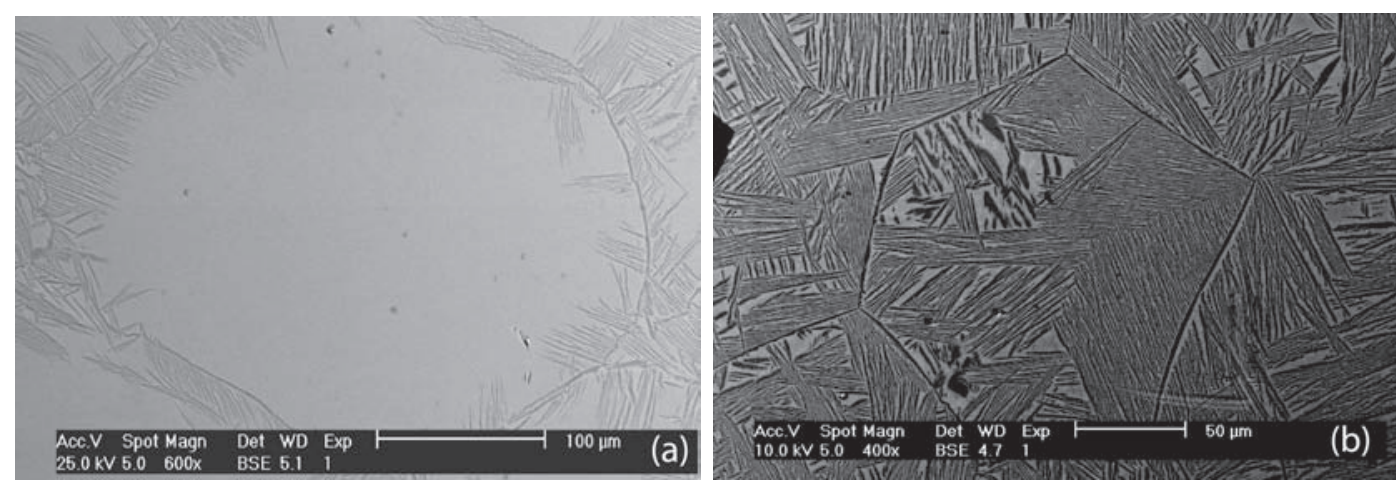

Fig. 5. SEM observations of the microstructures obtained by an isothermal treatment at $750^{\circ} \mathrm{C}$ during (a) $360 \mathrm{~s}$ and (b) $9400 \mathrm{~s}$.

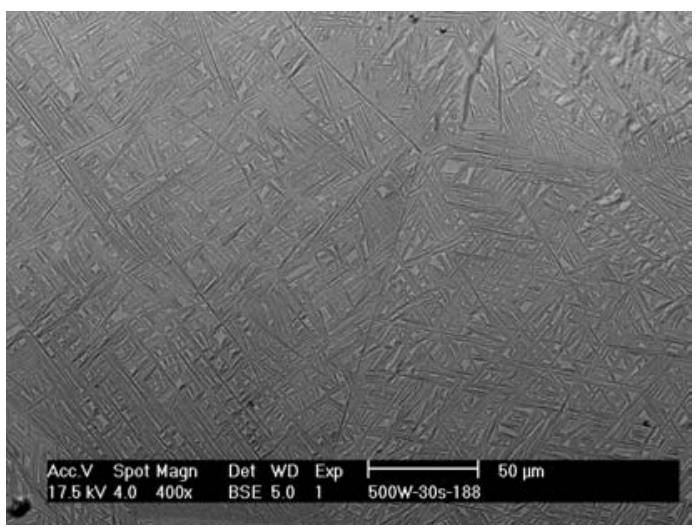

Fig. 6. SEM observations of the microstructure obtained by an isothermal treatment at $700{ }^{\circ} \mathrm{C}$ during $1500 \mathrm{~s}$. 

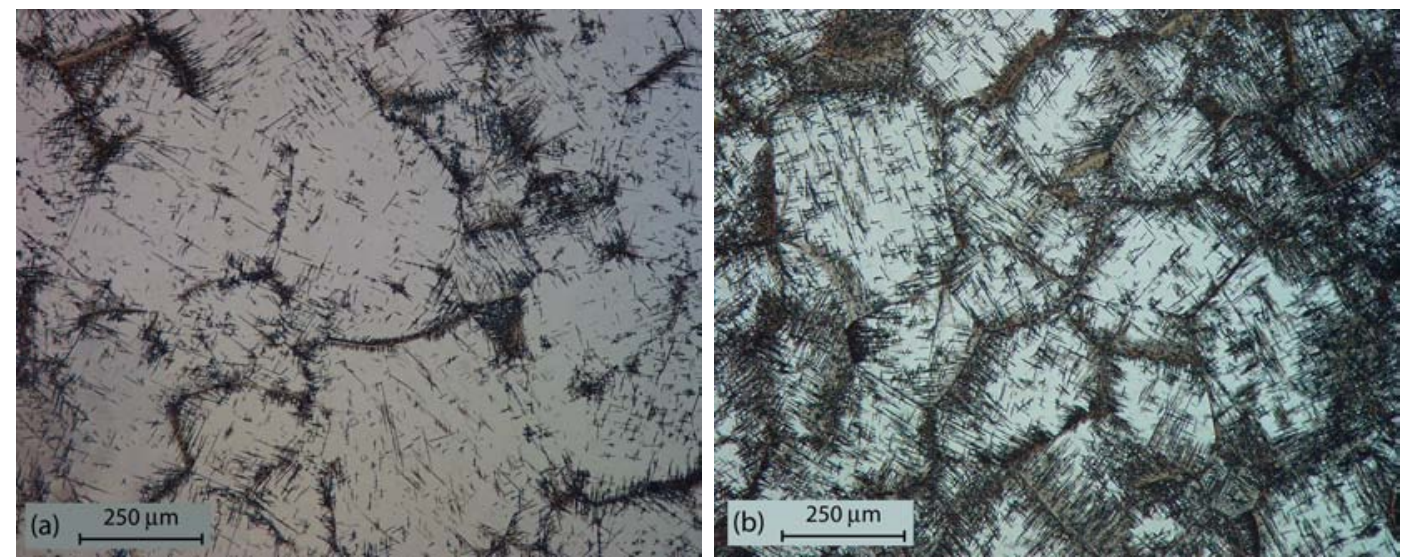

Fig. 7. Optical observations of the microstructures obtained by an isothermal treatment at $700{ }^{\circ} \mathrm{C}$ for (a) $500 \mathrm{~s}$ and (b) $800 \mathrm{~s}$.

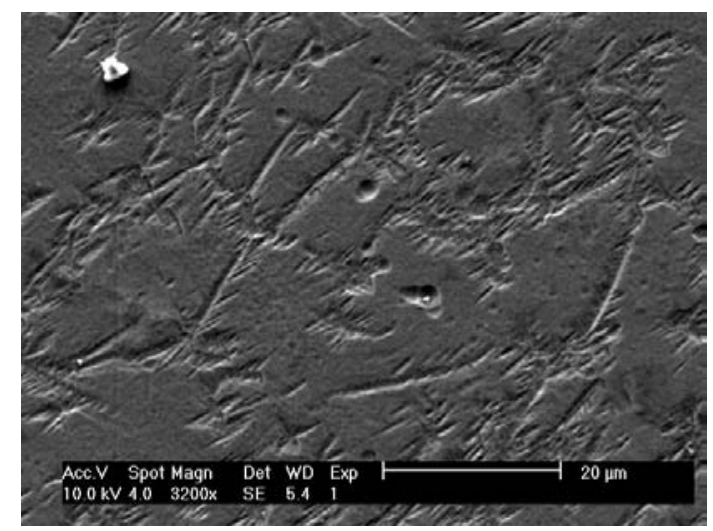

Fig. 8. SEM observations of the microstructure obtained by an isothermal treatment at $400{ }^{\circ} \mathrm{C}$ during $4400 \mathrm{~s}$. 


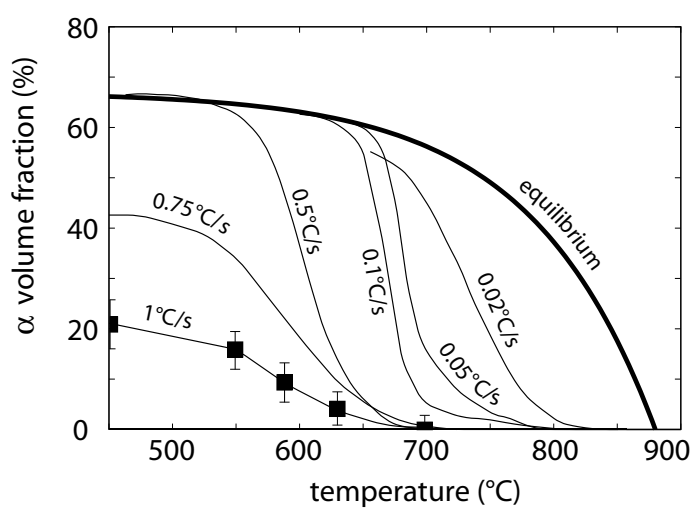

Fig. 9. Volume fraction of $\alpha$ vs. temperature for different cooling rates, obtained from X-Ray diffraction $\left(1^{\circ} \mathrm{C} / \mathrm{s}\right)$ and resistivity measurements (other rates).

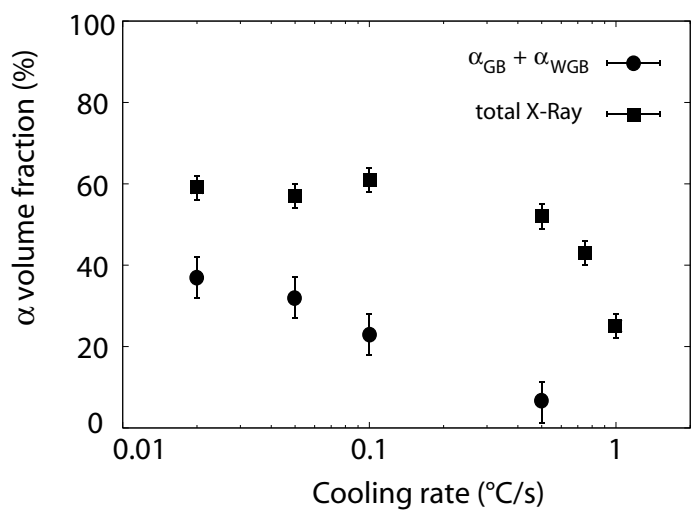

Fig. 10. Volume fraction of $\alpha$ and of $\alpha_{\mathrm{GB}+\mathrm{WGB}}$ at the end of the cooling treatment vs. cooling rate.
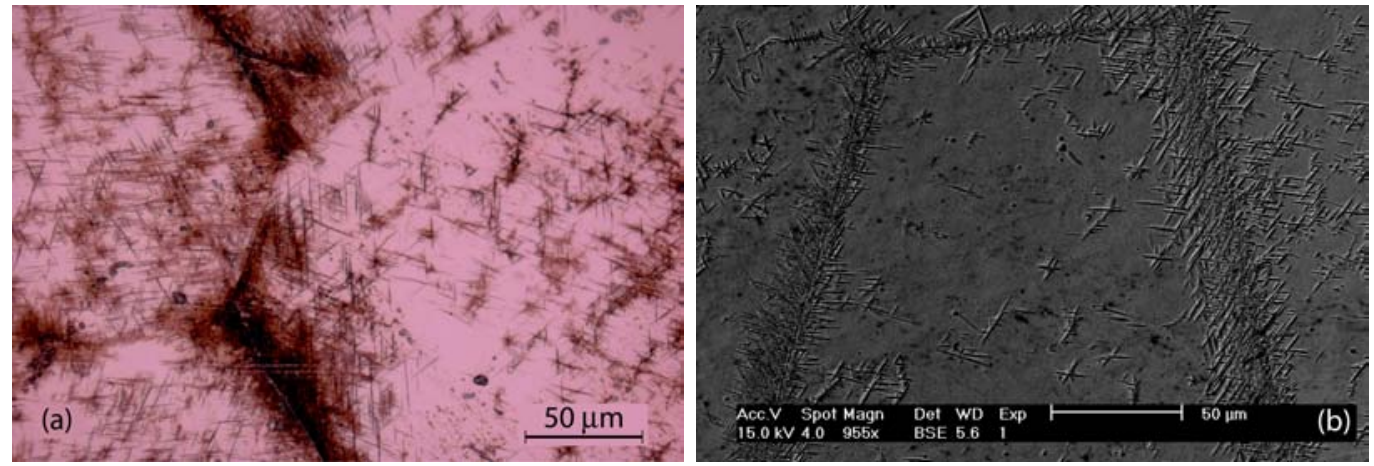

Fig. 11. Microstructures at the end of different cooling treatments: (a) $0.75{ }^{\circ} \mathrm{C} / \mathrm{s}$ (Optical); (b) $1{ }^{\circ} \mathrm{C} / \mathrm{s},(\mathrm{SEM})$. 

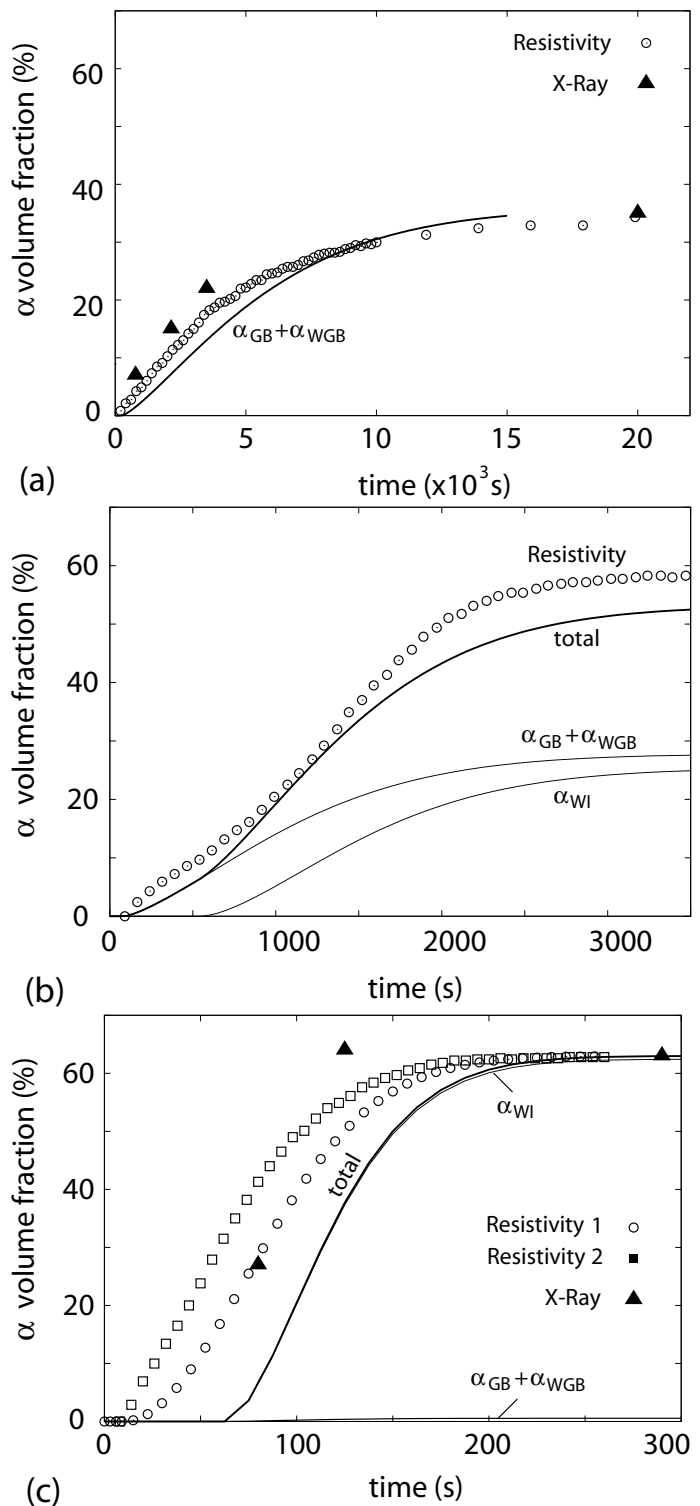

Fig. 12. Isothermal transformation kinetics at (a) 800, (b) 725 and (c) $600{ }^{\circ} \mathrm{C}$. Comparison between resistivity (open symbols), X-Ray Diffraction analysis (triangles) and calculations (continuous lines). 

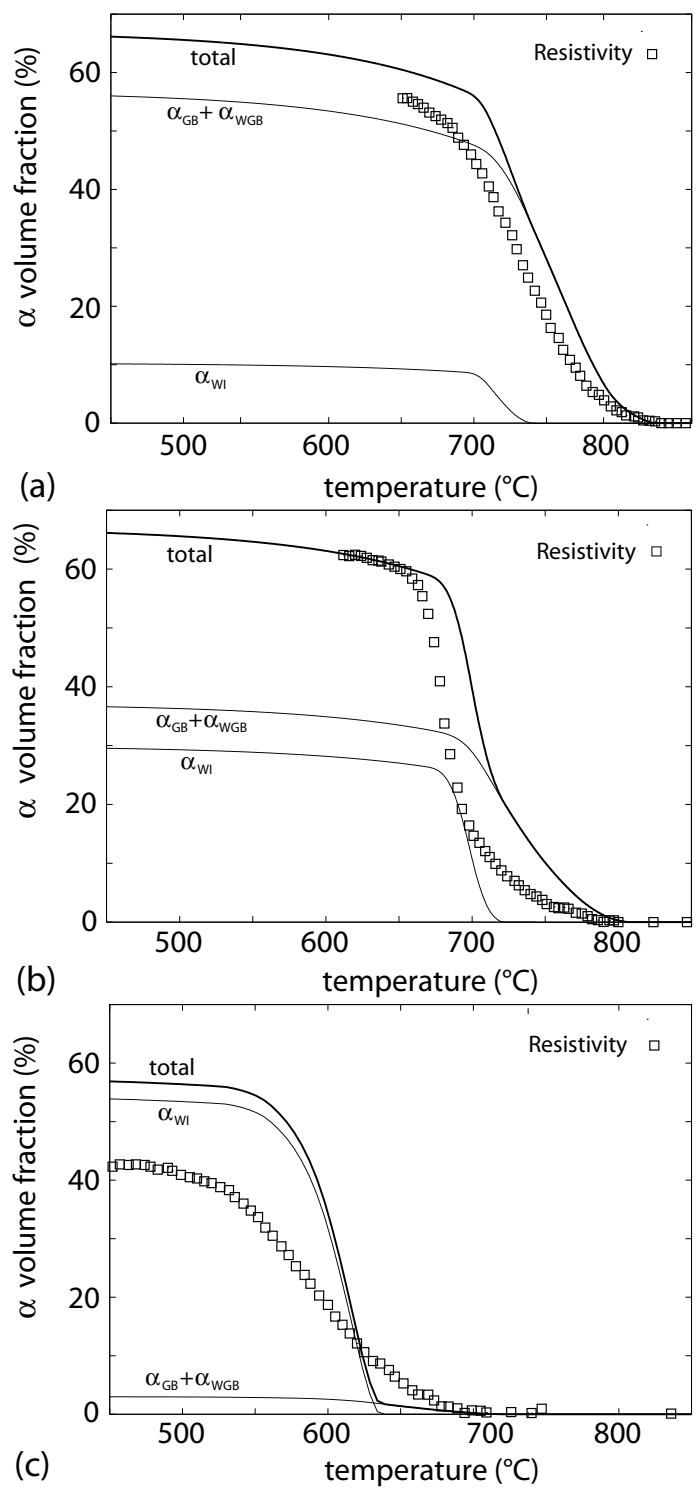

Fig. 13. Transformation kinetics during continuous cooling treatments at rates of (a) $0.02^{\circ} \mathrm{C} / \mathrm{s}$, (b) $0.05^{\circ} \mathrm{C} / \mathrm{s}$ and (c) $0.75{ }^{\circ} \mathrm{C} / \mathrm{s}$. Comparison between resistivity (open squares) and calculations (continuous lines). 


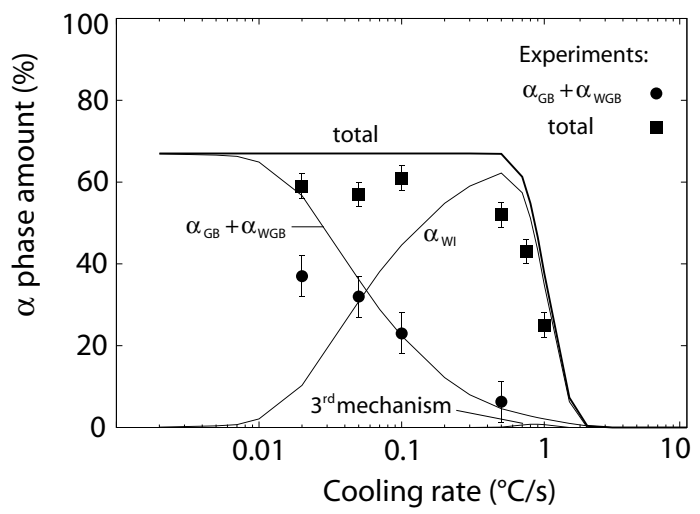

Fig. 14. Final volume fractions $f^{\alpha}$ of the different morphologies vs. cooling rates.
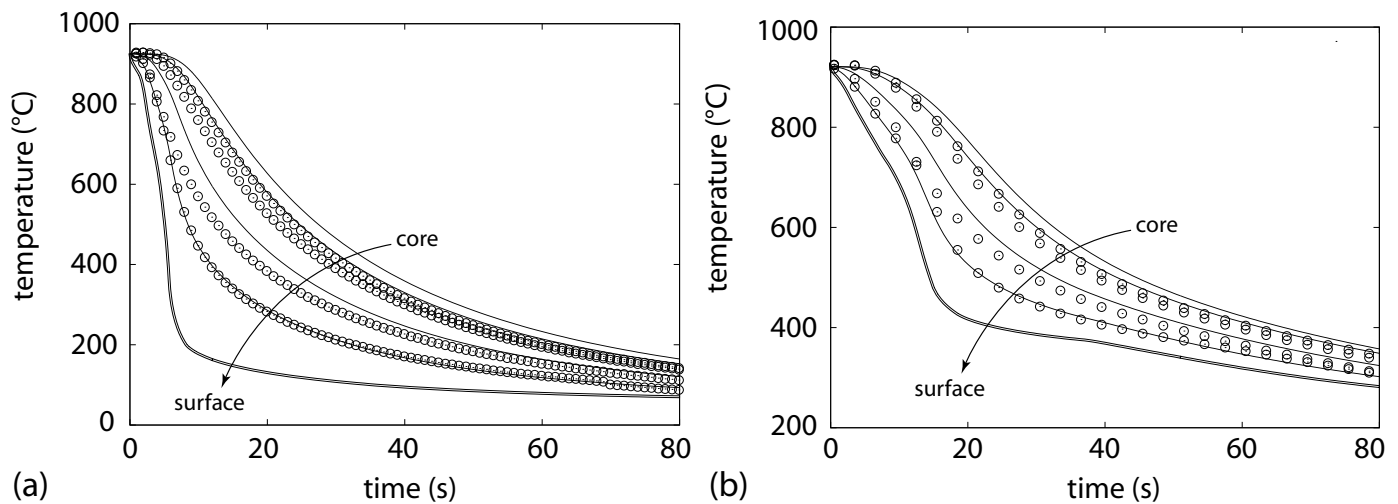

Fig. 15. Cooling curves at different locations during (a) water quenching; (b) oil quenching. The position are respectively $20,13,7$ and $3 \mathrm{~mm}$ along the radius from the surface. Dots are for the experiments and continuous lines for the calculations. The curve calculated at the surface is also given. 


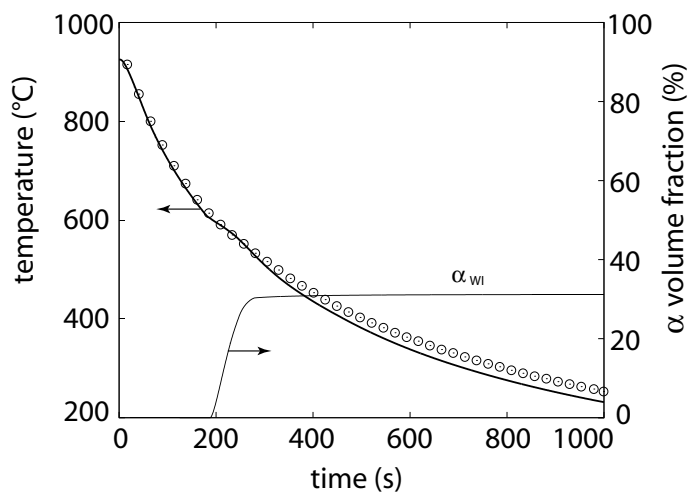

Fig. 16. Cooling curves (dots for experiments and continuous line for calculations) and calculated $\alpha_{\text {WI }}$ volume fraction evolution during an air cooling.

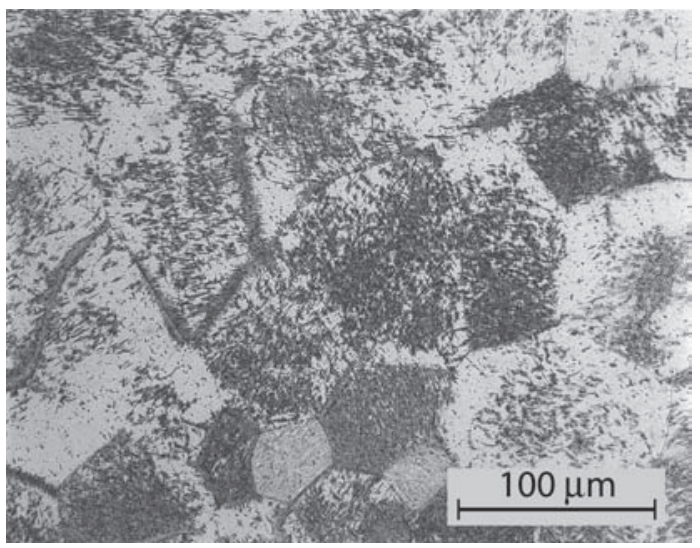

Fig. 17. Optical micrograph of the microstructure at the end of an air cooling.

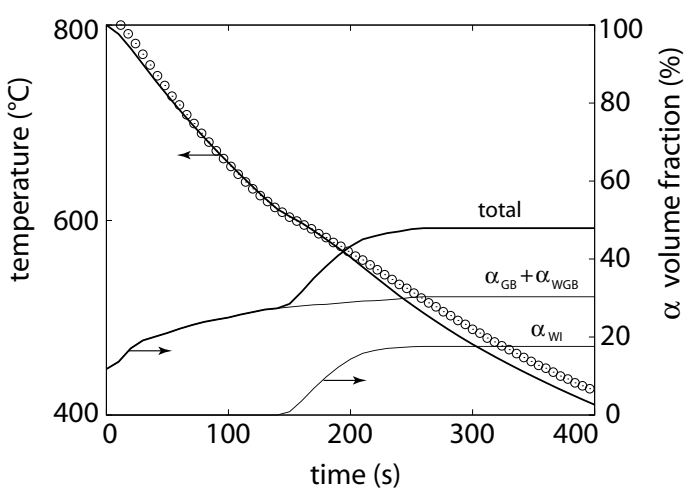

Fig. 18. Cooling curves (dots for the experiment and continuous line for the calculation) and calculated time evolution of the $\alpha$ phase volume fraction during an air cooling from $800^{\circ} \mathrm{C}$. 


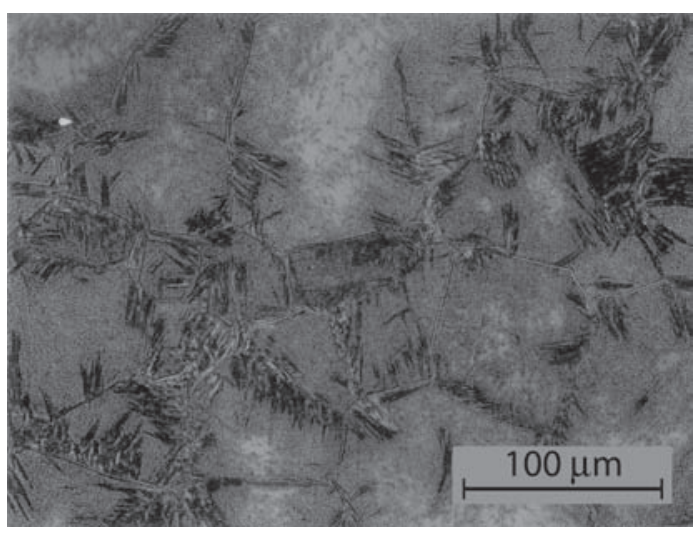

Fig. 19. Optical micrograph of the final microstructure at the end of an air cooling from $800^{\circ} \mathrm{C}$.
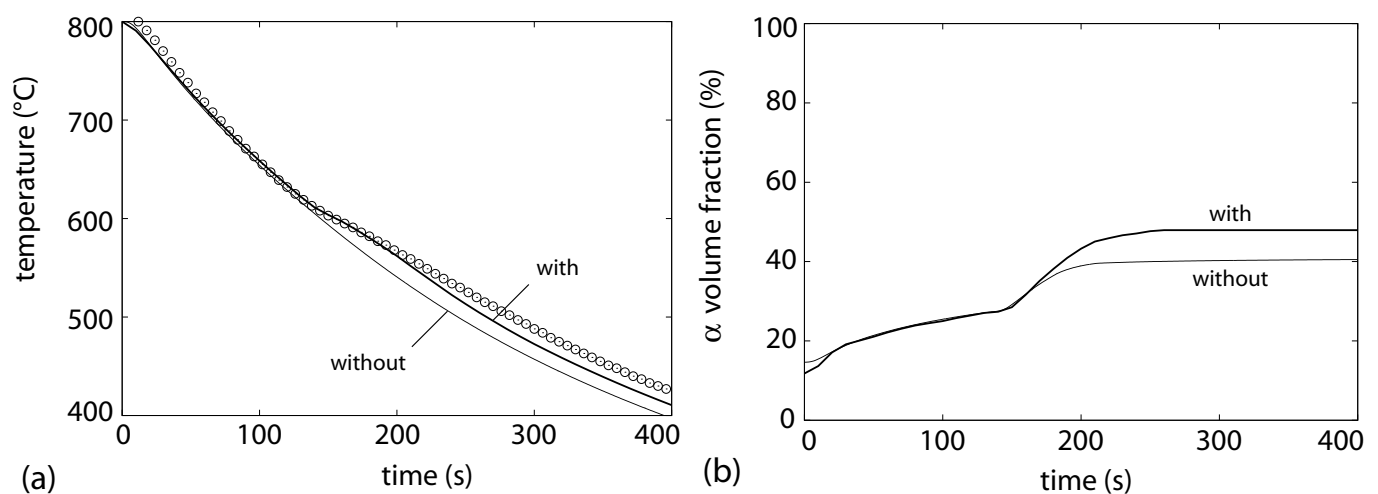

Fig. 20. (a) Cooling curves during an air cooling from $800^{\circ} \mathrm{C}$ : experiment, calculations with, and without heat release; (b) predicted $\alpha$ volume fractions.

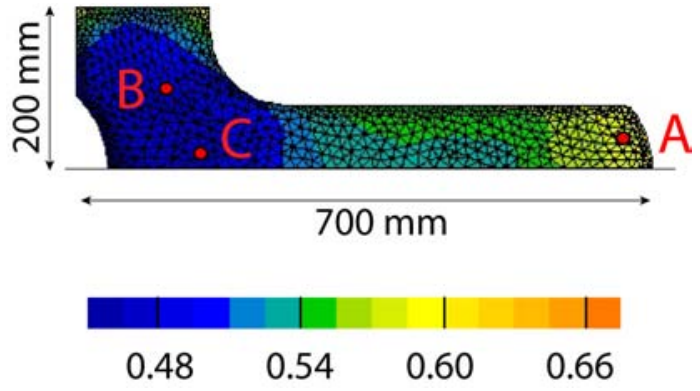

Fig. 21. Mesh superimposed to the final map of $\alpha_{\mathrm{WI}}$ volume fraction in a shaft disk. 

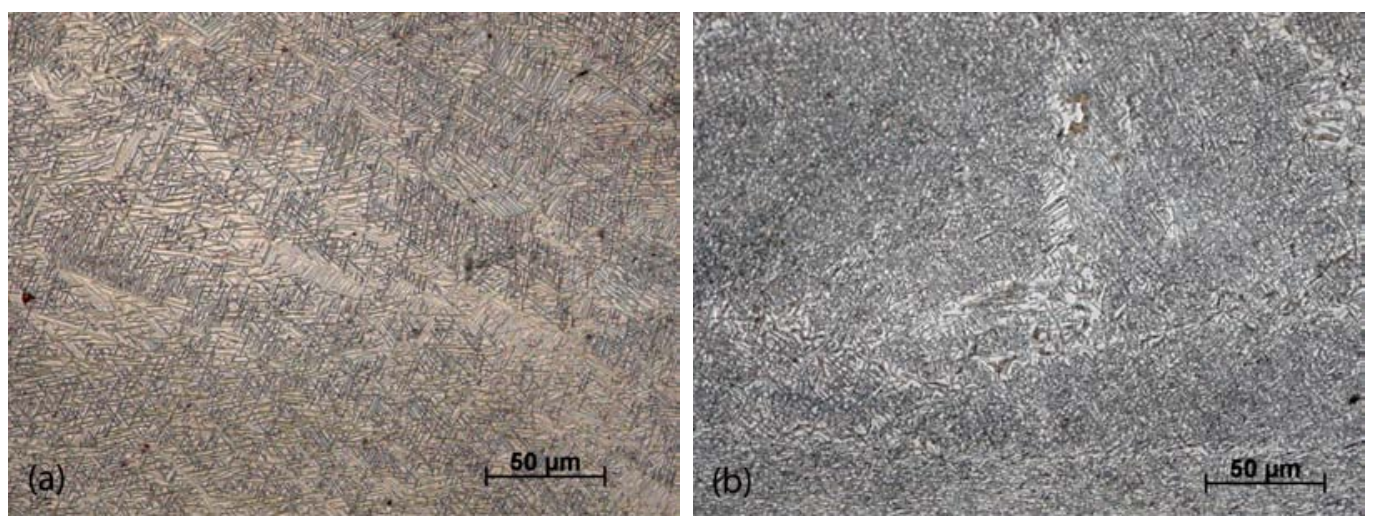

Fig. 22. Final microstructures observed by optical microscopy at points (a) A and

(b) B in Fig. 21. 